\title{
Analysis of Typical Automakers' Strategies for Meeting the Dual-Credit Regulations Regarding CAFC and NEVs
}

\author{
Yue Wang $^{1} \cdot$ Fuquan Zhao ${ }^{1} \cdot$ Yinshuo Yuan ${ }^{1} \cdot$ Han Hao $^{1} \cdot$ Zongwei Liu $^{1}$
}

Received: 25 May 2017 / Accepted: 8 October 2017 / Published online: 13 February 2018

(c) The Author(s) 2018. This article is an open access publication

\begin{abstract}
The parallel corporate average fuel consumption (CAFC) and new energy vehicle (NEV) credit schemes that have been introduced by the Ministry of Industry and Information Technology of China is an innovative attempt to simultaneously regulate conventional gasoline vehicles (CGVs) and NEVs in the passenger vehicle sector that is expected to function as a long-term management mechanism for CGVs to be more energy-efficient and NEVs to be well-promoted. This will have a significant impact on trends in China's automotive industry and automakers' business decisions. Taking the cases of four typical automakers with different levels of average fuel economy in their CGVs and advanced NEV production, scenario analysis has been applied to generate these automakers' alternatives in relation to compliance with the dual-credit regulations in force from 2017 to 2020 based on the Interim Measures on the Joint Management of CAFC and NEV Credits (Draft). These automakers' alternative approaches to compliance are compared. Further, in view of the financial losses as a result of halted production if they fail to comply, the values of CAFC and NEV credits and corresponding influencing factors are analyzed from the automakers' perspective. Finally, the most cost-effective compliance strategies for these automakers are summarized and suggested improvements in the regulations are proposed for the government.
\end{abstract}

Keywords Automotive industry $\cdot$ Dual-credit management $\cdot$ Credit trading market $\cdot$ Fuel consumption $\cdot$ New energy vehicle

\section{Introduction}

The automotive industry plays a key role in China's economy, and thus, its development provides powerful support for sustainable economic growth in China [1]. However, the rapid development of the automotive industry has resulted in increasing oil consumption in China [2]. China's oil dependence on foreign countries reached $64.4 \%$ in 2016 [3], up from $6.7 \%$ in 1993. Automobiles are one of the major sources of demand for oil, and thus, the development of energyefficient technologies is closely related to the nation's energy security [4]. Studies have shown an urgent need to control the rate of fuel consumption in China, especially in the ever-increasing passenger vehicle (PV) market $[5,6]$. Thus, increasingly stringent fuel consumption regulations are the inevitable strategic choice for China [7,8], and far-reaching

\section{Zongwei Liu}

liuzongwei@tsinghua.edu.cn

1 Tsinghua Automotive Strategy Research Institute, State Key Laboratory of Automotive Safety and Energy, Tsinghua University, Beijing 100084, China impacts on oil demand and greenhouse gas emissions are forecasted $[5,9,10]$.

Since 2016, China has begun to implement the fourthstage (Stage IV) fuel consumption regulations for PVs. Compared with the first three stages, the requirements for the application of energy-efficient technologies have been increased, posing significant challenges for automakers. Taking the national target as an example, average fuel consumption must improve from $6.9 \mathrm{~L} / 100 \mathrm{~km}$ in 2015 to $5.0 \mathrm{~L} / 100 \mathrm{~km}$ in 2020 , an annual improvement of $6.2 \%$. Moreover, the draft Interim Measures on the Joint Management of CAFC and NEV Credits (hereinafter referred to as the Draft) recently issued by the Ministry of Industry and Information Technology (MIIT) basically determines that the dual-credit regulations will come into effect in 2018, putting forward the new requirements for the production of new energy vehicles (NEVs) for medium-sized and large automakers, similar to the Zero Emission Vehicle mandate in California [11], which is a clear signal aimed at promoting the NEV market regardless of uncertainties in many aspects [12]. The regulations allow credit trading for NEVs, but not for corporate average fuel consumption (CAFC), and 
credit compensation is only permitted one way, from NEVs to CAFC. The compensation timeframe is one year, and negative credits need to be compensated during the following year. The dual-credit regulations, on the one hand, increase automakers' flexibility to meet the CAFC targets through compensation from NEV credits to CAFC credits, but, on the other hand, present a challenge in terms of product portfolios and technological improvements. It should be noted that NEVs already enjoy privileged status in CAFC calculations in Stage IV (without consideration of electricity consumption and with weights of 5 in 2016-2017, 3 in 2018-2019 and 2 in 2020.) [13]. Thus, producing NEVs will not only generate NEV credits for automakers, but will also lower the calculated CAFC. The latter effect is quite compelling given the stringent CAFC requirements in Stage IV. It is suggested that the development of energy-saving technologies and NEVs will determine core competitiveness under the regulations in the near future [14]. The enforced requirements of NEV credits are 8,10 , and $12 \%$ of conventional gasoline vehicle (CGV) production in 2018, 2019, and 2020, respectively, according to the draft. Recently, the China Association of Automobile Manufacturers (CAAM) has proposed that the requirements be modified to 5,8 , and $12 \%$ in 2018,2019 , and 2020 , respectively [15]. These requirements will affect shortterm compliance to some degree, as will be illustrated later. Due to space constraints, the draft details are not presented here.

Based on the draft, this study examines four types of automakers with different backgrounds and analyzes their ability to meet the new regulations over two timelines: (1) from 2016 to 2017 (using only calculated privileges for NEVs); and (2) from 2018 to 2020 (under the parallel dualcredit management). The automakers' profits or losses based on different technology portfolios are studied in the light of credit values, with several suggestions proposed for each type of automaker based on the findings. Finally, a simple evaluation of the potential of the NEV credit trading market is undertaken and compliance strategies are proposed for the different types of automakers.

\section{Methodology}

\subsection{Research Design}

Compliance situations for different automakers are analyzed according to the detailed management measures in response to the corresponding regulations $[12,16]$. For simplicity, NEV credit trading and credit transfers among automakers are not considered. Thus, the automakers have to comply with the regulations independently, making use of surplus NEV credits each year as well as a carryover of their previous years' CAFC credits. CAFC credits are valid for three years, and the coefficient of annual carryover is 0.8 until 2018 and 0.9 from 2019 onward [16]. Noncompliant automakers must halt the production of a certain number of gas-guzzling models and submit and execute an adjusted production or importation plan; otherwise, they will suffer punishments such as being forced to halt production of CGV models with fuel consumption that is higher than the target values [16]. It should be noted that punishment scenarios are beyond the scope of this study.

Four typical automakers, namely A, B, C, and D, were selected as case studies. Their potential to satisfy CAFC/NEV regulations separately is summarized in Table 1. Compliance scenarios in Stage IV are divided among the four typical automakers as follows. Scenario \#1: CAFC and NEV credits can meet both requirements each year. Scenario \#2 (the focus of this study): negative CAFC or NEV credits generated in the previous year will be offset in the current year, and CGV production will be reduced accordingly. In the following year, CGV production volume and product portfolios are assumed to be the same as in 2016, with the CGVs' average fuel consumption and the NEV production volume adjusted accordingly. Scenario \#3: negative CAFC or NEV credits generated in the previous year cannot be offset, even by halting all production of CGVs in the current year; thus, the automaker will be shut down.

For partly or totally noncompliant automakers (B, C, and D), the financial losses from halted production reflect the credit value from an internal perspective. The improvement in the CGVs' average fuel consumption (variable $V$ ) and the rate of growth of NEV production/NEV producing ratio (variable $W$ ) are chosen as key variables representing the automakers' business decisions. For $W$, automakers like C that produce NEV are represented by the growth rate of NEV production, while automakers like $\mathrm{B}$ and $\mathrm{D}$ that do not produce NEVs are represented by the NEV producing ratio, which is equal to the volume of NEV production divided by the volume of CGV production. By using these variables, the loss of production and corresponding loss of credit values, as well as compliance strategies in different years, can be discussed.

\subsection{Basic Information for Typical Automakers}

The four selected automakers (A, B, C, and D) all have relatively high market shares in the Chinese PV market and have distinct technological features, making the study more representative and authentic. The basic information regarding CGV and NEV production by these four automakers in 2016 is shown in Table 2. The CAFC of these automakers from 2013 to 2016 is presented in Table 3, shedding light on their technological level and potential for technological progress in the future. The progress rate refers to the average annual progress rate of CAFC from 2013 to 2015. 
Table 1 Classification of automakers and typical cases

\begin{tabular}{lll}
\hline & Compliance with the NEV credit & Noncompliance with the NEV credit \\
\hline Compliance with CAFC & A (homegrown NEV automakers) & B (joint venture automakers) \\
Noncompliance with CAFC & C (homegrown automakers with NEV production) & D (homegrown CGV automakers) \\
\hline
\end{tabular}

Table 2 Typical automakers' production information in 2016

\begin{tabular}{llll}
\hline Automakers & CGV (10,000 units) & BEV (10,000 units) & PHEV (10,000 units) \\
\hline A & 33.6 & 4.2 & 4.4 \\
B & 197.9 & 0 & 0 \\
C & 99.2 & 0.57 & 0 \\
D & 97.7 & (extremely few, negligible) & \\
\hline
\end{tabular}

Table 3 CAFC of typical automakers from 2013 to 2016

\begin{tabular}{lllllr}
\hline Automakers & \multicolumn{2}{l}{ CAFC in each year $(\mathrm{L} / 100 \mathrm{~km})$} & \multirow{2}{*}{ Progress rate } \\
\cline { 2 - 5 } & 2013 & 2014 & 2015 & 2016 & \\
\hline A & $6.71(\sqrt{ })$ & $6.75(\sqrt{ })$ & $6.75(\sqrt{ })$ & $2.92^{\mathrm{a}}\left(\sqrt{ }{ }^{\mathrm{b}}\right)$ & $-0.3 \%$ \\
B & $7.12(\sqrt{ })$ & $6.86(\sqrt{ })$ & $6.75(\sqrt{ })$ & $6.50^{\mathrm{a}}(\sqrt{ })$ & $2.6 \%$ \\
C & $6.55(\sqrt{ })$ & $6.66(\sqrt{ })$ & $7.01(\sqrt{ })$ & $7.20^{\mathrm{a}}(\times)$ & $-3.5 \%$ \\
D & $6.82(\sqrt{ })$ & $7.11(\sqrt{ })$ & $7.66(\sqrt{ })$ & $7.61^{\mathrm{a}}(\times)$ & $-6.0 \%$ \\
\hline
\end{tabular}

${ }^{a}$ NEVs enjoyed privileged status in CAFC calculations in 2016

$\mathrm{b} \sqrt{ }$ indicates CAFC compliance and $\times$ indicates noncompliance

\subsection{Analysis of CAFC Credit Values}

With enforced halted production of gas-guzzling models, which have more potential to increase negative CAFC credits, the noncompliant automakers' negative CAFC credits in the previous year $\left(Q_{\mathrm{CAFC}}\right)$ are not offset until the current year's forecasted positive CAFC credits reach a comparable level [16]. Halting production will not only have a negative impact on automakers' market shares, but will also result in reputational and financial losses. Due to the difficulty in quantifying losses in terms of market share and reputation, only financial losses are taken into consideration when calculating the credit values. Assume that the reduced production of model $i$ is $X_{i}$ units in year $y$, which is caused by noncompliance with CAFC requirements in year $y-1$. The value of these negative CAFC credits $\left(V_{\mathrm{CAFC}}\right)$ in year $y-1$ can be calculated using Eq. (1) $\left(P_{i}\right.$ represents the manufacturer's suggested retail price (MSRP) of model $i$ and $m$ is the profit margin).

$V_{\mathrm{CAFC}}=\frac{\sum X_{i} \times P_{i} \times m}{Q_{\mathrm{CAFC}}}$

The year in which negative CAFC credits are generated is called the compensated year, and the year in which these credits are offset is called the compensating year. The degree to which production is reduced in the compensating year will be affected by the variables $V$ and $W$, namely the rate of improvement in fuel consumption of CGVs and the growth rate of the NEV production/NEV producing ratio. When $V$ is fixed, the situation in the compensating year is determined by $W$. With low $W$, automakers cannot offset the negative credits of the previous year even by totally ceasing production in the compensating year; we define this situation as $V_{\mathrm{CAFC}}=\infty$. With medium $W$, automakers have to offset the negative credits by reducing $C G V$ production, and $V_{\mathrm{CAFC}}$ is a value between 0 and $\infty$. With high $W$, automakers can offset these credits without reducing production, and $V_{\mathrm{CAFC}}=0$. If $W$ is fixed, the credit values in the compensating year can be analyzed for different $V$ in the same way. When combining the changes in these two variables, a rough distribution diagram can be drawn of credit values in the compensating year. The CAFC credit value will fluctuate between 0 and infinity, as shown in Fig. 1. Area A corresponds to a credit value of 0 when negative credits can be offset without reducing production, and Area $\mathrm{C}$ corresponds to a credit value of infinity when negative credits cannot be offset at all. In Area $\mathrm{B}$, credit values range from 0 to infinity and negative credits can be offset by a certain reduction in production. In Area B, moving toward the upper right decreases the credit value and moving toward the lower left increases the credit value. Therefore, accelerating the improvement in CGV fuel consumption or improving the NEV production volume in the compensating year will lower the corresponding CAFC credit value, as well as the financial losses from curtailed production. 


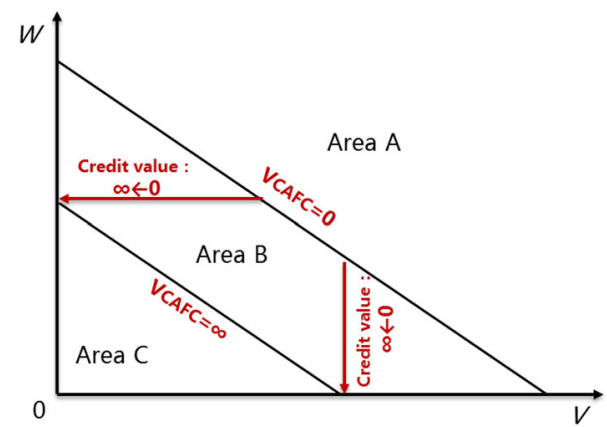

Fig. 1 Distribution of CAFC credit values

\subsection{Analysis of NEV Credit Values}

Automakers that fail to meet the previous year's NEV credit requirements must ensure that the reduction in the number of $\mathrm{CGVs}$ produced is no less than the number of negative NEV credits ( $Q_{\mathrm{NEV}}$ ) [16]. Similarly, NEV credit values can be calculated in terms of the financial losses from reduced production levels. Assume that the reduction in production of model $i$ is $Y_{i}$ units in year $y$, which is caused by noncompliance with NEV credit regulations in year $y-1$. The value of the negative NEV credits $\left(V_{\mathrm{NEV}}\right)$ in year $y-1$ can be calculated using Eq. (2). Each negative NEV credit corresponds to one less CGV produced. Therefore, the overall value of the NEV credits is determined by the product portfolio and output structure of the automaker, affected by the MSRP of gas-guzzling models because curtailing production of these models is a more effective way to bridge the CAFC gap. Therefore, the NEV credit values of automakers B, C, and $\mathrm{D}$ are 25,800 RMB/credit, 12,800 RMB/credit, and 24,100 $\mathrm{RMB} /$ credit, respectively. Larger failures in compliance may result in more models being taken out of production, thus causing a moderate change in the average NEV credit value for the automaker.

$V_{\mathrm{NEV}}=\frac{\sum Y_{i} \times P_{i} \times m}{Q_{\mathrm{NEV}}}$

\section{Compliance Strategies for Typical Automakers in Stage IV}

As mentioned above, the analysis of compliance by each automaker is conducted using two timelines. Hypotheses are also tested as follows. First, the automakers' CGV models and production volumes in the first year of each timeline are their 2016 figures, and the curb weight and MSRP of each model are those that applied in 2016. Second, variables $V$ and $W$ are constant throughout Stage IV for automakers A and $\mathrm{C}$ and are consistent among models. Third, the range of NEV models is that existing in 2016, so that the average
NEV credit for NEVs that are produced does not change. The average NEV credits for automakers B and D, who did not produce NEVs, are set at 3.5. Fourth, NEV production does not have any impact on CGV production. Finally, the profit margin for each vehicle produced is $10 \%$, and financial losses are measured in terms of RMB values in 2016.

\subsection{CAFC Credit Values and Compliance Strategies for Noncompliant Automakers in 2016 and 2017}

Automaker B had massive positive CAFC credits in 2016, as well as positive CAFC credits carried over from previous years. Consequently, B faces no pressure in complying with the CAFC requirements in 2017 , even without making any effort to improve their CGVs' fuel economy.

Automaker $\mathrm{C}$ did not meet the $\mathrm{CAFC}$ requirements in 2016 with credits that were carried over from 2013 to 2015. Consequently, about 160,000 negative CAFC credits need to be compensated in 2017. Using various values for $V$ and $W$, various reduced production situations in 2017, as well as the corresponding CAFC credit values for 2016, can be calculated as shown in Table 4.

The influence of changes in $V$ and $W$ can also be calculated, as indicated in Tables 5 and 6 , respectively. The results indicate that by reducing fuel consumption by $1.0 \%$ $(0.07 \mathrm{~L} / 100 \mathrm{~km})$, about 50,000-60,000 CGVs can continue to be produced, and thus, the potential financial losses can be reduced by 400-500 million RMB. Additionally, increasing NEV production by $50 \%$ (3000 NEVs) enables about $100,000 \mathrm{CGVs}$ to continue to be produced, and thus, the potential financial losses can be reduced by 800 million to 1 billion RMB. Overall, financial losses totaling hundreds of millions of RMB can be avoided by adopting different technological measures to decrease CAFC credit values. Due to the large number of negative CAFC credits generated in 2016, aggressive values for $V$ and $W$ are required if automaker $\mathrm{C}$ is to achieve compliance without curtailing production. For example, when $W$ is $200 \%$ (i.e., NEV production increases from 5700 units to 17,100 units), the minimum required $V$ is $6.7 \%$ (i.e., fuel economy improves from 7.2 to $6.7 \mathrm{~L} / 100 \mathrm{~km}$ ). Both requirements pose great challenges for automaker $\mathrm{C}$. Therefore, it might be wise for them to reduce the potential financial losses in 2017 as best they can, instead of attempting to maintain full production.

Automaker D did not meet the CAFC requirements in 2016, even after using the positive CAFC credits carried over from 2013 to 2015. There were about 275,000 negative CAFC credits to be compensated in 2017. To achieve compliance without curtailing production in 2017, D could choose to either achieve an NEV production ratio of $2.72 \%$ or improve the average fuel consumption of its CGVs by $12 \%$. Both choices are extremely challenging. 
Table 4 Changes in CAFC credit values (automaker C, 2016)

\begin{tabular}{|c|c|c|c|c|c|c|c|c|}
\hline \multirow{2}{*}{$\begin{array}{l}10,000 \text { units } \\
10,000 \mathrm{RMB} / \text { credit }\end{array}$} & \multicolumn{2}{|l|}{$W=50 \%$} & \multicolumn{2}{|l|}{$W=100 \%$} & \multicolumn{2}{|l|}{$W=150 \%$} & \multicolumn{2}{|l|}{$W=200 \%$} \\
\hline & Halted CGVs & Credit value & Halted CGVs & Credit value & Halted CGVs & Credit value & Halted CGVs & Credit value \\
\hline$V=0 \%$ & 67.5 & 3.78 & 53.0 & 3.07 & 41.0 & 2.50 & 33.0 & 2.28 \\
\hline$V=1.0 \%$ & 62.5 & 3.60 & 47.0 & 2.73 & 37.0 & 2.39 & 28.0 & 2.08 \\
\hline$V=2.0 \%$ & 57.5 & 3.32 & 42.0 & 2.53 & 32.0 & 2.26 & 22.0 & 1.75 \\
\hline$V=3.0 \%$ & 51.0 & 2.96 & 37.0 & 2.39 & 26.0 & 1.97 & 19.0 & 1.49 \\
\hline$V=4.0 \%$ & 43.0 & 2.56 & 31.0 & 2.23 & 21.0 & 1.65 & 14.5 & 1.14 \\
\hline$V=5.0 \%$ & 37.5 & 2.41 & 24.0 & 1.86 & 16.5 & 1.29 & 10.0 & 0.78 \\
\hline$V=6.0 \%$ & 30.0 & 2.19 & 19.0 & 1.49 & 12.0 & 0.94 & 4.0 & 0.31 \\
\hline
\end{tabular}

Table 5 Influences of increasing $W$ by an extra $50 \%^{\text {a }}$ when $V$ is fixed (automaker C, 2016)

\begin{tabular}{llll}
\hline$V(\%)$ & $\begin{array}{l}\text { Reduced number of } \\
\text { halted production (10,000 units) }\end{array}$ & $\begin{array}{l}\text { Reduced credit value } \\
(10,000 \mathrm{RMB} / \mathrm{credit})\end{array}$ & $\begin{array}{l}\text { Reduced financial losses } \\
(100 \text { million RMB) }\end{array}$ \\
\hline 0 & 11.5 & 0.50 & 8.15 \\
2.0 & 12.0 & 0.53 & 8.65 \\
4.0 & 9.7 & 0.48 & 7.80 \\
6.0 & 9.0 & 0.64 & 10.40 \\
\hline
\end{tabular}

a"Extra 50\%" means that in Table 4, the difference between adjacent columns of $W$ is $50 \%$. The data in Table 5 are the average of the difference after subtracting the right-hand column from the left-hand column in each pair of adjacent columns in Table 4

Table 6 Influences of increasing $V$ by an extra $1 \%^{\mathrm{a}}$ when $W$ is fixed (automaker $\mathrm{C}, 2016$ )

\begin{tabular}{llll}
\hline$W(\%)$ & $\begin{array}{l}\text { Reduced number of halted } \\
\text { production }(10,000 \text { units })\end{array}$ & $\begin{array}{l}\text { Reduced credit value } \\
(10,000 \text { RMB/credit })\end{array}$ & $\begin{array}{l}\text { Reduced financial } \\
\text { losses }(100 \text { million RMB) }\end{array}$ \\
\hline 50 & 6.3 & 0.27 & 4.40 \\
100 & 5.7 & 0.26 & 4.25 \\
150 & 4.8 & 0.26 & 4.25 \\
200 & 4.8 & 0.33 & 5.40 \\
\hline
\end{tabular}

a"Extra 1\%" in Table 6 has a similar meaning to "Extra 50\%" in Table 5

\subsection{CAFC Credit Values and Compliance Strategies for Noncompliant Automakers between 2018 and 2020}

First, it is assumed that automaker B does not produce NEVs in Stage IV. In that case, automaker B can meet the CAFC requirements in Stage IV when $V$ equals $4.83 \%$. However, they must still reduce CGV production by about 30,000 , 45,000 , and 70,000 units in 2018, 2019, and 2020, respectively, because of their noncompliance with the NEV credit requirements, with projected financial losses of hundreds of millions of RMB. Moreover, with reduced production of CGVs in effect, automaker B is not allowed to increase their annual production and sales. This will certainly place automaker B in a bad situation in the fiercely competitive market. If $V$ is less than $4.83 \%$, negative CAFC credits may arise in a certain year. Conversely, the CAFC required in 2018, 2019, and 2020 will be 120, 110, and 100\%, respectively, of the CAFC target in Stage IV, i.e., in 2019 and 2020 , it will be reduced by 8.33 and $9.09 \%$, respectively. The enhanced requirements are increasing much faster than improvements in the CGVs' average fuel consumption; thus, even more negative CAFC credits will be generated in the next year. CGV production will have to be significantly curtailed to compensate for these negative CAFC credits, and even if all production ceases, it is unlikely that these credits will be offset. Even automakers like B with advanced energy-efficient CGV technologies will find it difficult to absorb the significant costs in the next year once negative CAFC credits arise. Our calculations indicate that the CAFC credit value ranges from hundreds of thousands of RMB per credit to infinity, not to mention the loss of production as a result of noncompliance with NEV credit requirements. The above analysis indicates that to avoid significant financial losses, automakers like B should prepare for increased NEV production between 2018 and 2020, regardless of the exact value of $V$. 


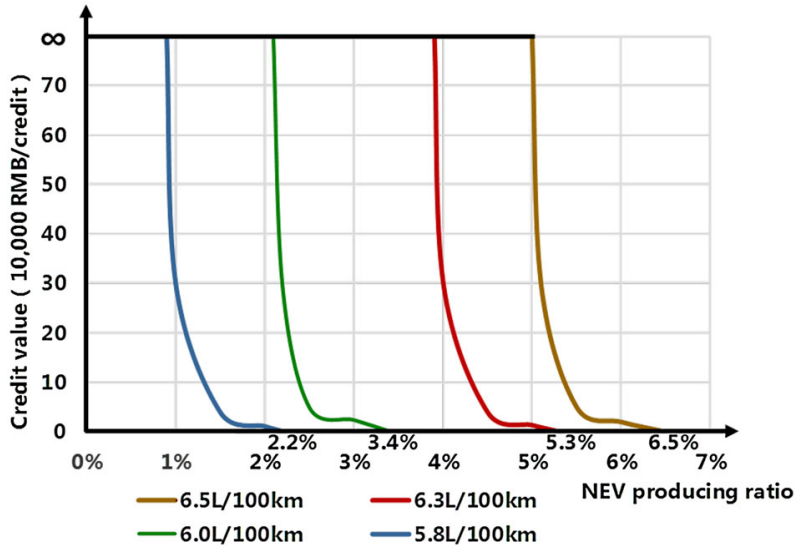

Fig. 2 Changes in CAFC credit values (automaker B, 2018)

The following analysis will assume that automaker B produces NEVs from 2019. The complying situations in 2018 and 2019 are considered first. Assuming that automaker B's average fuel consumption for CGVs does not improve between 2016 and 2018 (i.e., it remains at $6.5 \mathrm{~L} / 100 \mathrm{~km}$ ) and then starts to improve in 2019 , a total of 100,000 negative CAFC credits will be generated in 2018. Various scenarios in relation to reduced production in 2019 and CAFC credit values are shown in Fig. 2. It can be seen that increasing $W$ within a certain range can significantly reduce the credit value and thus the financial losses. When the average fuel consumption of CGVs is $6.5,6.3,6.0$, and $5.8 \mathrm{~L} / 100 \mathrm{~km}$, the minimum NEV producing ratios necessary to achieve compliance are $6.5,5.3,3.4$, and $2.2 \%$, respectively. In other words, a $0.1 \mathrm{~L} / 100 \mathrm{~km}$ improvement in the CGVs' average fuel consumption leads to approximately a $0.6 \%$ reduction in the NEV producing ratio. Next, the compliance situations in 2018 and 2020 are considered. $W$ is set to comply with each year's NEV credit requirements between 2018 and 2020, and the minimum $V$ is calculated accordingly, as shown in Table 7. In this case, the CGVs' average fuel consumption should reach $5.35 \mathrm{~L} / 100 \mathrm{~km}$ in 2020 to meet the CAFC requirements. Figure 3 shows various roadmaps regarding the CGVs' average fuel consumption given different rates of improvement.

For automaker C, the compliance situations in 2018 and 2019 are considered first. Different situations regarding

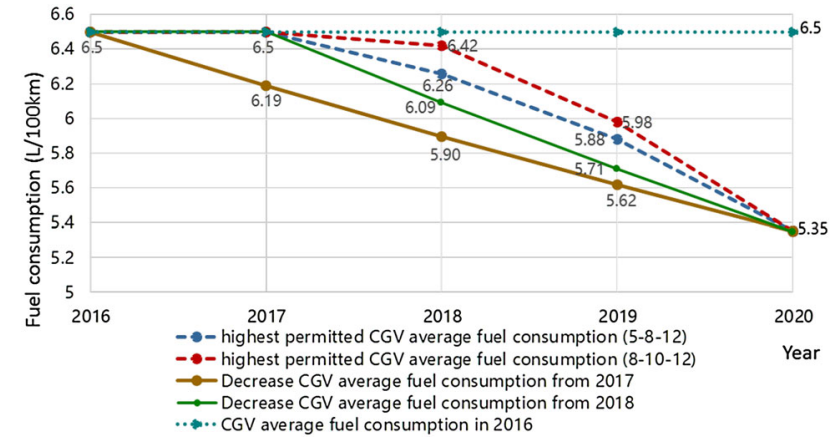

Fig. 3 Various roadmaps of CGVs' average fuel consumption (automaker B, Stage IV)

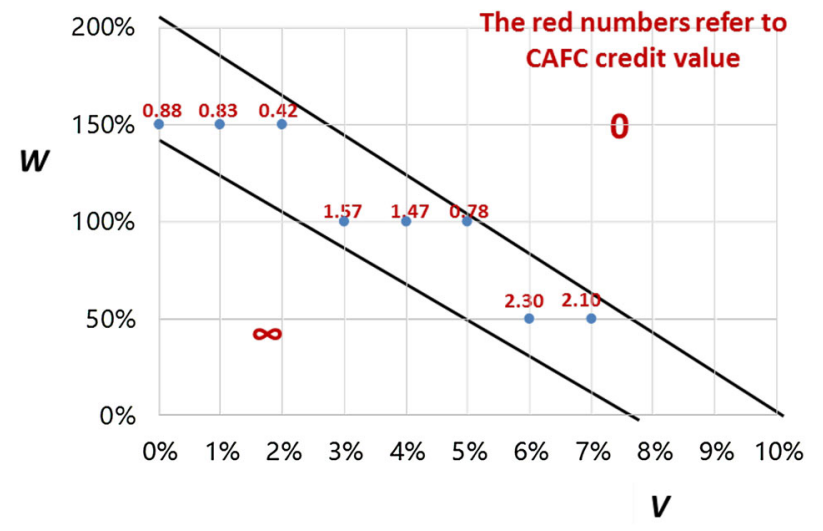

Fig. 4 Changes in CAFC credit values (automaker C, 2018)

reduced production in 2019 with different $V$ and $W$ values and the corresponding CAFC credit values are shown in Fig. 4. (The NEV credit requirements are assumed to be 5,8 and $12 \%$.) It is found that the CAFC credit value is lower in the scenario involving 'better development of NEVs with limited progress in improvement of CGVs' average fuel consumption' than in the scenario involving 'limited development of NEVs with significant improvement in CGVs' average fuel consumption.' The compliance situations in 2018 and 2020 are then considered, and the results are shown in Fig. 5. Whether the NEV credit requirements are 5, 8, and 12 or 8,10 , and $12 \%$ has little impact on the compliance situation regarding CAFC, while the required increases in NEV production are 71 and $116 \%$, respectively. Overall, for

Table 7 Compliance situations regarding duel-credit regulations (automaker B, 2018-2020)

\begin{tabular}{|c|c|c|c|c|c|c|}
\hline \multirow{2}{*}{$\begin{array}{l}\text { NEV credit requirement } \\
\text { from } 2018 \text { to } 2020(\%)\end{array}$} & \multicolumn{2}{|l|}{2018} & \multicolumn{2}{|l|}{2019} & \multicolumn{2}{|l|}{2020} \\
\hline & $\begin{array}{l}\text { Fuel consumption } \\
\text { of CGVs } \\
(\mathrm{L} / 100 \mathrm{~km})\end{array}$ & $\begin{array}{l}\text { NEV producing } \\
\text { ratio }(\%)\end{array}$ & $\begin{array}{l}\text { Fuel consumption } \\
\text { of CGVs } \\
(\mathrm{L} / 100 \mathrm{~km})\end{array}$ & $\begin{array}{l}\text { NEV producing } \\
\text { ratio }(\%)\end{array}$ & $\begin{array}{l}\text { Fuel consumption } \\
\text { of CGVs } \\
(\mathrm{L} / 100 \mathrm{~km})\end{array}$ & $\begin{array}{l}\mathrm{NEV} \text { producing } \\
\text { ratio }(\%)\end{array}$ \\
\hline $5-8-12$ & 6.26 & 1.43 & 5.88 & 2.29 & 5.35 & 3.43 \\
\hline $8-10-12$ & 6.42 & 2.29 & 5.98 & 2.86 & 5.35 & 3.43 \\
\hline
\end{tabular}



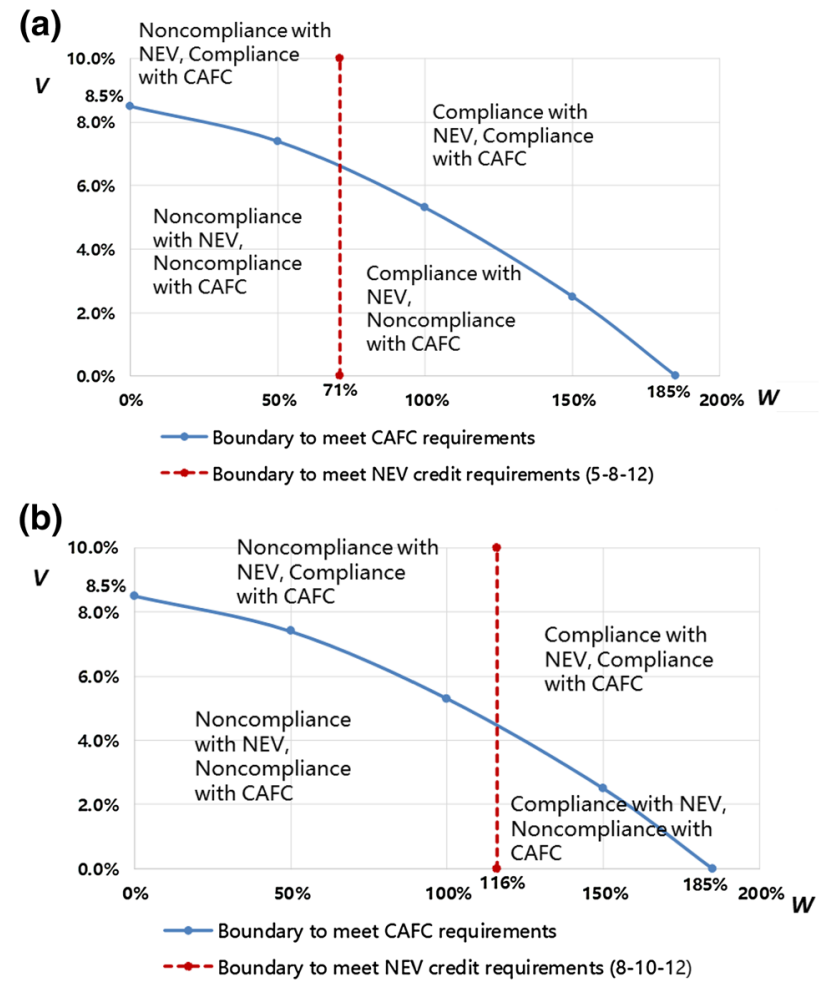

Fig. 5 a Compliance strategy patterns in response to the dual-credit regulations (automaker C, 2018-2020, 5, 8, and 12\%); b compliance strategy patterns in response to the dual-credit regulations (automaker C, 2018-2020, 8, 10, and 12\%)

automakers like $\mathrm{C}$, the best way to comply with the dualcredit regulations in Stage IV is to promote the production of NEVs and prioritize meeting the NEV credit requirements. Even if they fail to meet the CAFC requirements, the CAFC credit value will be distributed in the upper left zone in Fig. 4 and thus minimize the financial losses.

Automaker D lags in terms of energy-efficient technologies compared with automaker $\mathrm{B}$ and in terms of NEV development compared with automaker C. Thus, compliance with the dual-credit requirements is much tougher for automaker D. If there is no significant improvement in the CGVs' average fuel consumption or the NEV production level, automaker D will remain in Area C in Fig. 1 and will face declining production year after year. As a result, the CAFC credit values for automaker D will be extremely high, and automaker $\mathrm{D}$ is almost certain to shut down. The compliance situations for automaker D in 2018-2020 are considered in the same way as those for automaker $\mathrm{C}$, and the results are shown in Table 8. Automaker D's average fuel consumption for CGVs is $7.6 \mathrm{~L} / 100 \mathrm{~km}$ in 2016 , while the production volume of CGVs is 992,000 units. It can be seen that automakers like D face considerable pressure in terms of both energy-efficient technologies and NEV development, seeing that they are required to reduce fuel consumption in $2020-76 \%$ of that in 2016 and produce about 34,000 additional NEVs over this period.

\subsection{Analysis of Automaker A in Stage IV}

Automaker A produced 336,000 CGVs and 86,000 NEVs in 2016. Hence, the producing ratio of NEVs was more than $25 \%$. Even though automaker A makes no progress in terms of improving their CGVs' average fuel consumption and NEV production between 2017 and 2020, the regulations in Stage IV can easily be met. Further, automaker A will have about 250,000 positive NEV credits to sell annually between 2018 and 2020. Thus, automakers like A with a strong foundation in NEVs will obtain substantial benefits thanks to the dual-credit regulations, which confirms the government's intention to encourage first movers in NEV development. However, the fact that the average fuel consumption for automaker A's CGVs, which is around $7 \mathrm{~L} / 100 \mathrm{~km}$, can easily comply with CAFC requirements throughout Stage IV is not a good sign for promoting energy-efficient technologies in CGVs.

\section{Brief Summary of Typical Automakers' Compliance Strategies and Recommendations}

Based on the above analysis, compliance strategies in Stage IV for the four typical automakers are proposed as follows. Automakers like A have surplus NEV credits and can sell them to noncompliant automakers for extra benefits. These automakers can offer the NEV credits according to their

Table 8 Compliance situations in relation to the duel-credit regulations (automaker D, 2018-2020)

\begin{tabular}{|c|c|c|c|c|c|c|}
\hline \multirow{2}{*}{$\begin{array}{l}\text { NEV credit requirement } \\
\text { from } 2018 \text { to } 2020(\%)\end{array}$} & \multicolumn{2}{|l|}{2018} & \multicolumn{2}{|l|}{2019} & \multicolumn{2}{|l|}{2020} \\
\hline & $\begin{array}{l}\text { Fuel consumption } \\
\text { of } C G V s \\
(\mathrm{~L} / 100 \mathrm{~km})\end{array}$ & $\begin{array}{l}\text { NEV producing } \\
\text { ratio }(\%)\end{array}$ & $\begin{array}{l}\text { Fuel consumption } \\
\text { of CGVs } \\
(\mathrm{L} / 100 \mathrm{~km})\end{array}$ & $\begin{array}{l}\text { NEV producing } \\
\text { ratio }(\%)\end{array}$ & $\begin{array}{l}\text { Fuel consumption } \\
\text { of CGVs } \\
(\mathrm{L} / 100 \mathrm{~km})\end{array}$ & $\begin{array}{l}\text { NEV producing } \\
\text { ratio }(\%)\end{array}$ \\
\hline $5-8-12$ & 6.82 & 1.43 & 6.41 & 2.29 & 5.82 & 3.43 \\
\hline $8-10-12$ & 6.99 & 2.29 & 6.51 & 2.86 & 5.82 & 3.43 \\
\hline
\end{tabular}


costs, business strategies, and the relative strengths of supply and demand in the NEV credit market. Automakers like B cannot neglect the upgrading of their CGVs' energy-saving technologies while promoting the development of NEVs. To meet the NEV credit requirements, these automakers need to introduce NEVs to the market as soon as possible and transform from a CGV producer to a balanced producer. The application of energy-saving technologies needs to be planned in advance to avoid noncompliance with $\mathrm{CAFC}$ requirements and alleviate compliance pressure later in Stage IV. Automakers like C are lagging behind in terms of energy-saving technologies, and thus, vigorous development of NEVs is an ideal choice to enable compliance in Stage IV. The development of NEVs not only ensures compliance with the NEV credit requirements, but also helps to substantially reduce the calculated CAFC, easing the potential difficulty in complying with CAFC regulations. However, the shortcomings in their CGVs' fuel economy must be overcome in pursuit of sustainable development given the definite trend in China toward more stringent regulations. Automakers like D are lagging behind in terms of both energy-saving technologies and NEV development. These automakers should be aware of their deficiencies and significant potential for improvement. It is suggested that they should immediately develop long-term compliance strategies based on their current situation either by forming alliances with others or by significantly altering the direction of their development. It should be noted that the above analysis is based merely on the financial perspective; however, automakers' real-world decision-making is also based on their business strategies.

It is predicted that in the NEV credit trading market, automakers like A will become the major sellers. Due to the private nature of credit trading activities among automakers, the exact price of NEV credits may be difficult to ascertain, and differences may exist for various purchasers. In view of the limited number of players in the market, market manipulation might become an issue and thus warrants further research in terms of gaming scenarios. Further lessons can be learned from California's ZEV credit trading market. Automakers may calculate the exact CAFC credit cost in terms of technological upgrades and compare it to the purchase price plus the trading cost. Before an open trading platform for NEV credits can be set up, there are many uncertainties in the credit trading market that need to be resolved, and automakers will need to comply independently, as in the scenarios analyzed in this study. The NEV credit trading market will offer a supplementary way for automakers to comply with the regulations, which is suitable for short-term compliance but is not a sustainable way to remain competitive. Last but not least, considering the compliance situation of automaker A, it is suggested that the priority NEVs that are set to enjoy in Stage V should be eliminated to avoid stifling progress in energy-efficient technologies for CGVs, i.e., the 'leakage effect' noted by other studies $[17,18]$.

\section{Conclusions}

In this study, four representative automakers in the Chinese market were selected and a detailed scenario analysis of various compliance situations in relation to dual-credit regulations in Stage IV was presented based on the draft recently issued by the MIIT. From the perspective of financial losses as a result of curtailed production, it was found that CAFC credit values vary significantly among three types of noncompliant automakers under various situations, while the NEV credit value generally equals the profit from one CGV. Automakers should adopt the most cost-effective compliance strategy after a comprehensive evaluation of their redundancy technologies and cost-control capabilities. Noncompliant automakers need to comprehensively assess their compliance strategies based on both their internal situation and external information. In conclusion, the proposed dual-credit regulations relating to CAFC and NEVs will pose further challenges to automakers' product portfolios and technical decision-making, together with more flexibility in compliance. Lost production results in not only massive financial losses but also loss of market share and reputational damage. Automakers should never cease to pursue optimization of their portfolios of energy-saving technologies for their CGV fleet and their NEV fleet portfolios in response to increasingly stringent regulations.

Acknowledgements This study is sponsored by the Natural Science Foundation of Beijing (9162008) and Ministry of Science and Technology of China (ZLY2015017).

Open Access This article is distributed under the terms of the Creative Commons Attribution 4.0 International License (http://creativecomm ons.org/licenses/by/4.0/), which permits unrestricted use, distribution, and reproduction in any medium, provided you give appropriate credit to the original author(s) and the source, provide a link to the Creative Commons license, and indicate if changes were made.

\section{References}

1. Zhao, F., Liu, Z.: Action orientation in building China into a stronger automotive country. Auto Ind. Res. 10, 4-7 (2014)

2. Zhang, G.B.: Energy and automotive industry development. Auto Saf. 3, 22-25 (2014)

3. Zhao, X.: China's oil dependence on foreign countries reached $65 \%$ in 2016. China Petrochem. 2, 15 (2017)

4. Liu, Z., Liu, F., Wang, Y., et al.: Integrated study of CAFC, NEV and carbon credits on portfolio policy suggestions. Chin. J. Automot. Eng. 1, 1-9 (2017)

5. Huo, H., Wang, M., Zhang, X., et al.: Projection of energy use and greenhouse gas emissions by motor vehicles in China: policy options and impacts. Energy Policy 43(3), 37-48 (2012) 
6. China Energy Research Society: China Energy Outlook. Economic Management Press, Beijing (2016)

7. He, H., Bandivadekar, A.: Passenger car fuel-efficiency standards in China and the US: stringency and technology. 2020-2025. http:// theicct.org/node/610 (2013)

8. Zhao, F., Hao, H., Liu, Z.: Technology strategy to meet China's $\mathrm{L} / 100 \mathrm{~km}$ fuel consumption target for passenger vehicles in 2020. Clean Technol. Environ. Policy 18(1), 7-15 (2016)

9. Zhou, G., Ou, X., Zhang, X.: Development of electric vehicles use in China: a study from the perspective of life-cycle energy consumption and greenhouse gas emissions. Energy Policy 59(3), 875-884 (2013)

10. Ma, H., Balthasar, F., Tait, N., et al.: A new comparison between the life cycle greenhouse gas emissions of battery electric vehicles and internal combustion vehicles. Energy Policy 44(5), 160-173 (2012)

11. CARB: The ZEV regulation. https://www.arb.ca.gov/msprog/ zevprog/zevprog.htm

12. Morton, C., Anable, J., Brand, C.: Policy making under uncertainty in electric vehicle demand. Energy 167(167), 125-138 (2014)
13. Standardization Administration of China: GB 27999-2014 Evaluation Approaches and Indexes on Passenger Car Fuel Consumption. China Standards Press, Beijing (2014)

14. Zhao, F., Liu, Z.: Analysis of homegrown enterprises positioning from the strategic perspective of strong automotive country. Auto Sci. Technol. 6, 1-5 (2014)

15. Overseas merger and acquisition of automobiles. Future NEV credit market scene simulation under the new policies of "dual credits management". http://www.d1EV.com (2017)

16. The Ministry of Industry and Information Technology of China: Interim measures on the joint management of CAFC and NEV credits (draft). http://www.miit.gov.cn/n1146295/n1652858/ n1653100/n3767755/c5261365/content.html (2016)

17. Jenn, A., Azevedo, I.M.L., Michalek, J.J.: Alternative fuel vehicle adoption increases fleet gasoline consumption and greenhouse gas emissions under United States corporate average fuel economy policy and greenhouse gas emissions standards. Environ. Sci. Technol. 50(5), 2165 (2016)

18. Lutsey, N., Sperling, D.: Regulatory adaptation: accommodating electric vehicles in a petroleum world. Energy Policy 45(2), 308316 (2012) 